\title{
Multimodality Treatment For Peritoneal Mesothelioma: A Single Center Experience
}

\section{Peritoneal Mezotelyomanın Multimodal Tedavisi: Tek Merkez Deneyimi}

\author{
Özgen Ahmet Yıldırım ${ }^{1}$, Bulent Aksel², Umut Demırc1 ${ }^{3}$ \\ ${ }^{1}$ Gazi Yaşargil Eğtim Ve Araştırma Hastanesi, İç Hastalıkları Kliniği, Tıbbi Onkoloji, Diyarbakır \\ ${ }^{2}$ Sağılık Bilimleri Üniversitesi Dr Abdurrahman Yurtarslan Onkoloji Eğitim Ve Araştırma Hastanesi, Cerrahi \\ Onkoloji Kliniği, Ankara \\ ${ }^{3}$ Memorial Ankara Hastanesi, Tıbbi Onkoloji Kliniği, Ankara
}

Dergiye Ulaşma Tarihi: 10.06.2020 Dergiye Kabul Tarihi: 16.09.2020 Doi: 10.5505/aot.2020.71931

\section{ÖZET}

GİRIŞ ve AMAÇ: Sitoredüktif cerrahi (SRC) ve hipertermik intraperitoneal kemoterapi (HIPEC) peritoneal mezotelyoma (PM) için önerilen tedavi yaklaşımıdır. Burada PM için multimodal tedavi deneyimimizi sunuyoruz.

YÖNTEM ve GEREÇLER: Ocak 2009 ve Aralık 2017 tarihleri arasında otuz sekiz hasta çalışmaya dahil edildi. Hastaların kliniko-patolojik özellikleri, tedavi sonuçları, tıbbi kayıtları ve intraoperatif peritoneal kanser indeksi (PCI) skorları geriye dönük olarak analiz edildi.

BULGULAR: Ortanca yaşı 61 (21-80) olan toplam 38 hasta $(n=22$ kadın) değerlendirildi. 23 hastaya $(\%$ 60.5) SRC uyguland ve 18 hastaya (\% 47.3) SRC + HIPEC uyguland1. Postoperatif erken mortal vakalar (6 hasta) hariç tutulduktan sonra, adjuvan tedavi ile tedavi edilen hastalarda daha uzun OS elde edildi ( $\mathrm{p}=0.03)$. Morbid seyri olan hastalarda PCI değeri daha yüksekti. Obezite, diyabetes mellitus (DM) ve CA125 seviyeleri 1000 U / ml'nin üzerinde olan hastalarda morbidite daha yüksekti.

TARTIŞMA ve SONUÇ: Adjuvan kemoterapinin SRC + HIPEC uygulanan PM hastalarında OS'yi iyileştirebileceğini göstermiştir. Bununla birlikte, DM, yüksek PCI değeri ve ameliyat öncesi CA125 düzeyleri $1000 \mathrm{IU} /$ ml'nin üzerinde olan PM hastalarında çoklu tedavi dikkatle değerlendirilmelidir.

Anahtar Kelimeler: peritoneal mezotelyoma, sitoredüktif cerrahi, hipertermik intraperitoneal kemoterapi

\section{ABSTRACT}

INTRODUCTION: Cytoreductive surgery (SRC) and hyperthermic intraperitoneal chemotherapy (HIPEC) is the recommended treatment approach for peritoneal mesothelioma (PM). Here we present our multimodal treatment experience for PM.

METHODS: Thirty-eight patients were included in the study between January 2009 and December 2017. Clinico-pathological features and treatment results, medical records and intraoperative peritoneal cancer index (PCI) scores of the patients were analyzed retrospectively.

RESULTS: A total of 38 patients $(n=22$ women) with a median age of 61 (21-80) were evaluated. SRC was applied to 23 patients (60.5\%) and SRC + HIPEC was applied to 18 patients (47.3\%). After excluding postoperative early mortal cases (6 patients), longer OS was achieved in patients treated with adjuvant therapy ( $p$ $=0.03)$. PCI value was higher in patients with morbid course. Morbidity was higher in patients with obesity, diabetes mellitus (DM) and CA125 levels above $1000 \mathrm{U} / \mathrm{ml}$.

DISCUSSION AND CONCLUSION: It has shown that adjuvant chemotherapy can improve OS in PM patients receiving SRC + HIPEC. However, multimodal treatments should be carefully evaluated in patients with DM, high PCI, and preoperative CA125 levels above $1000 \mathrm{IU} / \mathrm{ml}$.

Keywords: peritoneal mesothelioma, cytoreductive surgery, hypertermic intraperitoneal chemotherapy

\section{Giriş ve Amaç}

Malignperitonealmezotelyoma (MPM), asbest ile güçlü bir ilişkisi olan agresif ve tedaviye dirençli bir periton neoplazmıdır. Hastalık insidansı yılda milyonda birdir. Uzun süreli asbest maruziyeti, 30 y1l içinde hastalığın gelişmesine neden olur. Son y1llarda MPM insidansiartmaktadir . Hastalik 25-71 yaşlarında ortaya çıkabilir $(1,2)$ 
Tümörün ve assitinperitoneal birikimi, hastalığın ana sunumu olan karın ağrısı ve distansiyona neden olur. İlk semptomlardan tanıya kadar geçen ortalama süre 122 gündür. Ortanca genel sağkalım 12 aydır ve çoğunlukla bağırsak tıkanıklığı ve malnütrisyon ile ölüm gerçekleşir (3).

Hipertermikintraperitoneal kemoterapi (HIPEC) ile birlikte sitoredüktif cerrahi (SRC) uygulanmasının iyi seçilmiş vakalarda hastalığın seyrini önemli ölçüde iyileştirdiği gösterilmiştir(3).

Amerikan Ortak Kanser Komitesi (AJCC) evreleme k1lavuzunun 8 . baskıs1, plevral mezotelyoma için bir evreleme sistemine sahiptir, ancak MPM için bir evreleme sistemine sahip değildir.41 Bu sorunu çözmek için, Yan ve arkadaşları tarafindan yeni bir TNM evreleme sistemi önerilmiştir. $\mathrm{Bu}$ sistemde $\mathrm{T}$, intraoperatif olarak ölçülen peritoneal kanser indeksi (PCI) ile hastalık yükü dört alt gruba ayrılmıştır: T1 (PCI 1-10), T2 (PCI 11-20), T3 (PCI 21-30), ve T4 (PCI 31-39). Cerrahi örneklerin histopatolojisine göre pozitif lenf düğümlerinin varlığı (N1) veya yokluğu (N0) değerlendirilmiştir. Preoperatif görüntülemede tesbit edilen herhangi bir ekstra abdominal metastaz M1 olarak adlandırılmıştır. Evre I hastalığ 1 T1N0M0, evre II T2-3N0M0 ve evre III, T4N0M0 ve N1 veya M1 hastalığını içermiştir. $\mathrm{Bu}$ evreleme sistemi kullanıldığında, evre I, II ve III hastalık için 5 yıllık sağkalım sırası ile \% $87, \% 53$, ve $\% 29$ olarak tesbit edilmiştir $(4,5)$.

Burada, tedavinin modalitesinin belirlenmesinde hasta seçimi için bir bakış açısı sağlamak amacıyla MPM'de SRC + HIPEC, adjuvan kemoterapi ve palyatif kemoterapinin aktivitesini ve olumsuz özelliklerini göstermeyi amaçladık, ayrıca son literatürü gözden geçirdik.

\section{Yöntem ve Gereçler}

Ocak 2009 - Aralık 2017 tarihleri arasında Sağlık Bilimleri Üniversitesi Dr Abdurrahman Yurtarslan Onkoloji Eğitim ve Araştırma hastanesindeki tek merkez tecrübemizi sunduk.Otuz sekiz hasta çalışmaya alındı. Hastaların klinik-patolojik özellikleri ve tedavi sonuçları geriye dönük olarak hastaların tıbbi kayıtları ile analiz edildi. Peritoneal yüzeyin 13 bölgesindeki tümör yükü bazında 0-39 PCI skorlar1 hesapland1 ve hastalar sirasiyla 1-10,
11-20 ve> 20 skorlarıly üç kategoriye ayrıldı.SRC prosedürü cerrahın çıplak gözle görülebilir tüm tümörleri rezeke etmesi esasına dayanır. HIPEC uygulamasında; Mitomisin C gibi sitotoksik ajanların yüksek 1sıda invitro ve invivo olarak sitotoksik etkinliklerinin arttığ tesbit edilmiş ve 1 sıtılmış kemoterapotik ajanın uygulanmas1 intraperitoneal kemoterapinin temel yaklaşımı haline gelmiştir. Isıtma prosedürü ekstrakorporeal olarak konveksiyon tipi isitici cihazda serum fizyolojik içerisindeki sitotoksik ajanın isitilip abdominal kaviteye verilmesini kapsar. Prosedür süresince sitotoksik solüsyon tekrar ekstrakorporeal dolaşıma alınıp isitilarak 40-43 derece aralığındaki isisi korunur (6).

Retrospektif çalışmalar ile ilgili etik kurul onayı kapsamında Sağlık Bilimleri Üniversitesi Dr Abdurrahman Yurtarslan Onkoloji Eğitim ve Araştırma hastanesi Etik Kurulundan onay alınmıştır.

\section{İstatistiksel Analiz}

Tüm istatistiksel analizler Statistical PackagefortheSocialSciences software program version 21.0 (SPSS Inc., Chicago, IL, USA) ile yapıldı. Hasta gruplarının özellikleri arasındaki fark Mann- Whitney U test veya Chi-Square testi ile değerlendirildi.

\section{Sonuçlar}

Ortanca yaş1 61 (21-80) olan toplam 38 hasta ( $\mathrm{n}=22$ kadın) değerlendirildi. Tüm hastalar epitheloid tipte peritonealmezotelyoma idi. 23 hastaya (\% 60.5) SRC uyguland ve 18 hastaya (\% 47.3) SRC + HIPEC uyguland. HIPEC, açık teknik ile, 60 dakika içinde $42{ }^{\circ} \mathrm{C}$ bir karın içi sıcaklığı ile gerçekleştirildi. Mitomisinli (12 mg / m2 / 1) sisplatin (80 mg / $\mathrm{m} 2$ / 1) intraperitonal olarak yap1ld. Postoperatif 2 ayda 6 hasta (\% 15.8) öldü, üç hastada ölüm neden sepsis idi. Ölen hastaların tamamının preoperatif CA125 seviyeleri 1000 $\mathrm{U} /$ ml'nin üzerindeydi ve beşinde diyabetesmellitus (DM) vard1. Yedi hastaya (\% 18.4) adjuvan kemoterapi ve iki hastaya neoadjuvan kemoterapi verildi (tablo 1).

Radyolojik ve intraoperatifperitoneal kanser indeksi (PCI) skorlaması, tüm hastalarda tanımland,, ortalama PCI 14 idi. 1000'den yüksek ca125 seviyeleri olan 6 hastanın tümünde PCI verileri 20'nin üzerindeydi.

Opere edilen hastaların medyan PSK ve GSK ortanca değerleri sırasıyla 7 ay (0.4-13.5 ay) ve 
18 ay (0-57.4 ay) idi. Opere olmayan hastaların PSK değeri 5 ay (0.5-11), GSK değeri 11 ay (2-24) olarak sonuçlanmıştır. Opere olan ve olmayan hastalar karşılaştıııldığında GSK farkı istatistiksel olara anlamlıdır $(\mathrm{p}=0.04)$. HIPEC uygulanan hastalar ile opere olmayan hastalar karşılaştıııldı̆̆ında yine GSK açısından istatistiksel anlamlı fark izlenmiştir $(\mathrm{p}=0.03)$ Postoperatif erken mortal vakalar (6 hasta) hariç tutulduktan sonra adjuvan tedavi ile tedavi edilen hastalarda daha uzun OS elde edildi. Ortalma OS adjuvan tedavi grubunda 75 ay (31.8-118.2 ay) ve adjuvan olmayan tedavi grubunda 18 ay $(2.7-34$ ay) idi $(\mathrm{p}=0.03)$. Toplamda 7 hastaya adjuvan kemoterapi uygulanmıştır. Hasta sayısının adjuvan tedavi grubunda düşük olması ve OS neticesinin 6 hastada gerçekleşmesi nedeni ile istatistiksel olarak ortanca hesabı yapılması mümkün olmamıştır (tablo 1).

Birinci basamak sistemik kemoterapiler sisplatin ile pemetrekset $(\mathrm{n}=18, \%$ 47.4), karboplatin ile pemetrekset $(\mathrm{n}=5, \%$ 13.2), sisplatin ile gemsitabin $(\mathrm{n}=2, \% 5.2)$ ve tek ajangemsitabin $(\mathrm{n}=1, \% 2.6)$ idi. . İkinci basamak kemoterapiler gemsitabin $(\mathrm{n}=3)$, pemetrekset $(\mathrm{n}=1)$ ve sisplatin ile pemetrekset $(\mathrm{n}=1)$ idi. İkinci basamak kemoterapi alan hastalar, ikinci basamak kemoterapi almayan hastalardan sayısal olarak daha uzun ortalama OS elde etmişlerdir (32.6 aylara karşı 16.9 ay, $\mathrm{p}=0.123)$.

\section{Tartışma}

Peritonealkarsinomatoza yaklaşımlar jinekolojik ve gastrointestinalmalignitelerdedaha detaylı çalışılmıştır. SRC ve HIPEC verileri peritonealmezotelyomada diğer histolojilere göre sinırlıdır. $\mathrm{Bu}$ çalışmada klinik deneyimlerimizi sunmayı ve hasta seçimi için bir perspektif sağlamayıamaçladık.

MPM'da sistemik kemoterapi, hastalığın doğal seyrini kontrol etmek için zayıftır. Mevcut bilgilere göre, sistemik kemoterapinin birincil yaklaşım olarak tek bir yöntem olarak kullanılması, palyatif yaklaşım dışında tarihsel bir değere sahiptir. $(7,8)$ SRC ve HIPEC, seçilmiş hastalarda son yıllarda öne çıkan tedavi yaklaşımıdır $(9,10)$. SRC ve HIPEC'in eklenmesi genel sağkalımda (OS) ve progresyonsuzsağkalımda (PFS) önemli bir artış sağlamıştır $(11,12)$. HIPEC'de, SRC prosedürü ile makroskopik tümör volümü uzaklaştırıldıktan sonra mikroskopik hastalığın eradikasyonunu amaçlayan birçok kemoterapötik ajan kullanılmıştır. Hangi terapötik ajanın kullanılacağı hala tartışma konusudur. Sisplatin, sisplatin ile doksorubisin, tek başına mitomisin-C veya doksorubisin ile kombinasyonu; yayınlanmış serilerde aktif ajanlar olarak gösterilmiştir (8). Ek olarak oksaliplatin bu prosedürde ümit vaat eden aktivite gerçekleştirmiştir (13).

Tablo 1: Hastaların demografik verileri

Hasta $(n=38)$

\begin{tabular}{|c|c|}
\hline Cinsiyet (kadın: $n(\%)$ & $22(57 \%)$ \\
\hline Yaş ortanca (min-max) & $61(21-80)$ \\
\hline Ca 125 ortalama $(+-s d)$ & $675(+-693)$ \\
\hline Diyabet : $n(\%)$ & $9(23 \%)$ \\
\hline Performans status (ortanca) & \\
\hline$S R C$ & 1 \\
\hline$S R C+H I P E C$ & 1 \\
\hline Adjuvan alan grup & 1 \\
\hline Adjuvan almayan grup & 1 \\
\hline Opere olmayan & 2 \\
\hline PCI : ortalama $(+-s d)$ & $14(+-9)$ \\
\hline Erken postop exitus $n(\%)$ & $6(16 \%)$ \\
\hline$P S K \quad$ (ay) (min-max) & \\
\hline (ortanca) & $7(0.4-13.5)$ \\
\hline$S R C$ & $5(0.5-11)$ \\
\hline $\begin{array}{l}\text { Opere olmayan } \\
\text { p değeri }\end{array}$ & 0.07 \\
\hline$G S K(a y)$ & \\
\hline SRC (ortanca) & $18(0-57.4)$ \\
\hline SRC + HIPEC (ortanca) & $21(0-57.4)$ \\
\hline Opere olmayan (ortanca) & $11(2-24)$ \\
\hline$p$ değgeri: $* * *$ & 0.04 ve $0.03 * * *$ \\
\hline $\begin{array}{l}\text { Adjuvan alan grup (ortalma } \\
\text { * }\end{array}$ & $\begin{array}{l}75(31.8-118.2) \\
18(2.7-34)\end{array}$ \\
\hline $\begin{array}{l}\text { Adjuvan almayan grup } \\
\text { (ortalama)* } \\
\text { p değeri: }\end{array}$ & 0.03 \\
\hline$S R C: n(\%)$ & $23(60.5 \%)$ \\
\hline HIPEC: $n(\%)$ & $18(47.3 \%)$ \\
\hline
\end{tabular}

Sd: standart deviasyon, SRC: sitoredüktif cerrahi, HIPEC: hipertermik intraperitoneal kemoterapi, PSK: progresyonsuz sağ kalım, GSK: genel sağ kalım, PCI peritoneal kanser indeksi *: postop erken mortal hastalar dahil edilmemiştir. Performans status değerlendirmesinde ECOG skorlaması kullanılmıştır. ***: sirası ile SRC opere olmayan, SRC+HIPEC - opere olmayan karşılaştırmaları. 
Mümkün olan en iyi deneyimi elde etmek için hasta seçimi anahtar faktördür,tedavi yönteminin etkinliği ile birlikte ciddi komplikasyon risklerimeydana gelmektedir. Peritoneal kanser indeksi, periton yayılımı olan malignitelerde cerrahi müdahaleler için iyi tanımlanmış tedaviye bağlı bir prognostik belirteçtir (9). 1000'den fazla Ca125 seviyesi ve yüksek PCI, erken postoperatifmortalite ile ilişkili bulunmuştur.

Çalışmamızın kısıtlayıcı yanı; bu nadir histolojide istatistiksel değerlendirmeler yapmak için yeterli sayıda hastamızın olmamas1 idi. Bununla birlikte, 1000 U / ml'den fazla CA125 seviyesine sahip 6 hastada> 20 PCI değeri vard1, sepsis ve erken mortalite gibi ciddi komplikasyonlar ortaya çıktı. Tümör yükü ve peritoneal kanser indeksi gibi birincil cerrahi faktörlerin yanı sıra; yaş, diyabet ve kardiyovasküler hastalık gibi sistemik komorbiditeler de tedavi sonucunu güçlü bir şekilde etkileyen özelliklerdir. Ameliyat sonrası erken dönemde ölen 6 hastanın 5'i diyabetikti.

Çalışmamız tek merkezli ve sınırlı hasta sayılı olsa da izole periton mezotelyoması ender bir antitedir. Hastaların başvurudaki performans statusları genellikle kötüdür ve çoklu tedavileri tolere etmeleri çoğunlukla mümkün olmamaktadır. $\mathrm{Bu}$ bağlamda yaptığımız değerlendirme önemlidir. Adjuvan kemoterapinin SRC + HIPEC uygulanan PM hastalarında OS'yi iyileştirebileceği konusunda istatistiksel açıdan anlamlı veri elde edilmiştir. Bununla birlikte, DM, yüksek PCI değeri ve ameliyat öncesi CA125 düzeylerinin $1000 \mathrm{IU} /$ ml'nin üzerinde olması PM hastalarında tedavinin dikkatle değerlendirilmesini gerektirmektedir.

\section{Kaynaklar}

1. H. Sharma, I. Bell, J. Schofield,G.Bird.Primary peritoneal mesothelioma: Case series and literature review. Clinics and Research in Hepatology and Gastroenterology, 201101-01, Volume 35, Issue 1, Pages 55-59

2. Michele Carbone, Bevan H. Ly, Ronald F. Dodson, IanPagano, Paul T. Morris, Umran A. Dogan, Adi F. Gazdar,Harvey I. Pass, Haining Yang. Malignant Mesothelioma: Facts, Myths and
Hypotheses J Cell Physiol. 2012 Jan; 227(1): 44-58

3. De Panghermanzini. Malignant peritoneal mesothelioma. Tumori. 2005 JanFeb;91(1):1-5

4. AJCC Cancer Staging Manual. 8th ed. Springer International Publishing; 2018.

5. A novel tumor-node-metastasis (TNM) staging system of diffuse malignant peritoneal mesothelioma using outcome analysis of a multi-institutional database*.Yan TD, Deraco M, Elias D, Glehen O, Levine EA, Moran BJ, Morris DL, Chua TC, Piso P, Sugarbaker PH, Peritoneal Surface Oncology Group.Cancer. 2011 May 1; 117(9):185563.

6. Engelhardt R. Hyperthermia and drugs. Recent Results. Cancer Res 1987;104:136203.

7. Eltabbakh GH, Piver MS, Hempling RE, Recio FO, Intengen ME.Clinicalpicture, responsetotherapy, andsurvival of women with diffuse malignant peritoneal mesothelioma. J SurgOncol. 1999 Jan;70(1):6-12

8. Antman $\mathrm{K}^{1}$, Shemin R, Ryan L, Klegar K, Osteen R, Herman T, Lederman G, Corson J. Malignant mesothelioma: prognostic variables in a registry of 180 patients, the Dana-Farber Cancer Institute and Brigham and Women's Hospital experience over two decades, 1965-1985. J ClinOncol. 1988 Jan;6(1):147-53

9. Tan $\mathrm{GH}^{1}$, Cheung M, Chanyaputhipong J, Soo KC, Teo MC.Cytoreductive surgery (CRS) and hyperthermic intraperitoneal chemotherapy (HIPEC) for peritoneal mesothelioma.Ann A cad MedSingapore. 2013 Jun;42(6):291-6

10. Goslin B, Sevak S, Siripong A et al.Outcomes of cytoreduction with hyperthermic intraperitoneal chemotherapy: our experience at a midwest community hospital. Am J Surg203:383 - 3862012

11. Yan TD, Welch L, Black D, Sugarbaker PH. A systematicreview on theefficacy of cytoreductive surgery combined with perioperative intraperitoneal chemotherapy for diffuse malignancy peritoneal mesothelioma. AnnOncol2007;18:827-34 
12. Sugarbaker PH, Yan TD, Stuart OA, Yoo D. Comprehensive management of diffuse malignant peritoneal mesothelioma. Eur J SurgOncol2006;32:686-91.

13. Hubert J, Thiboutot E, Dubé P, Cloutier AS, Drolet P. Cytoreductive surgery and hyperthermic intraperitoneal chemotherapy with oxaliplatin for peritoneal mesothelioma: preliminary results and survive alanalysis. SiderisL.SurgOncol. 2015 Mar;24(1):41-6. doi: 10.1016/j.suronc.2014.12.002. Epub 2015 Jan 8 